\title{
Guidelines for green design of cooking appliances
}

\author{
Jianfang Zong*, Jianwei Tian, Dongfeng Gao, Xin Zhang \\ China National Institute of Standardization, No.4 Zhichun Road, Haidian District, Beijing, 100191
}

\begin{abstract}
This paper explains the purpose and basic principles, requirements, process and key points, main methods, evaluation and improvement of the eco-design of cooking appliances. This paper also provides guidelines for cooking appliances manufacturing enterprises to standardize their practice, and guides them for green design of cooking appliances, which is of great significance in promoting the transformation and upgrade of cooking appliances, improving the standard for green manufacturing, and increasing the supply of green products.
\end{abstract}

Gas cooking appliance is a general term of cookware with a gas cooking appliance, including gas stove, gas oven, gas roaster, gas range, gas baking oven, gas rice cooker, integrated cooking appliance and gas-electric cooking appliance, hereinafter referred to as "cooking appliances". Cooking appliances are important consumer goods in Chinese people's life. As urbanization is continuously carried out and people's income is increasingly rising, great progress and development has been made in cooking appliance manufacturing industry in recent years, which facilitats the improvement of life quality and economic development. Chinese government and competent authorities pay close attention to the production and quality of cooking appliances and have issued several laws, regulations and policies beneficial to sound and sustainable development of the industry. People's demand on cooking appliances is exactly the development direction for cooking appliances market. Accordingly, the development direction of cooking appliances market is subject to meeting consumer's evergrowing needs for cooking appliances, that is, the industry will grow in an energy-efficient, functional, intelligent and ecological way. Eco-design of cooking appliances will conform to consumption upgrading, increase the supply of green products and solve the problem of low thermal efficiency, poor waste gas treatment and material selection, allowing consumers to choose and use green products so as to relieve the pressure on resources and energy, and reduce the adverse impact on the environment and the mankind.

Green design of cooking appliances is also known as "design with environmental awareness", "eco-design" or "environmental design", which means the activity of introducing environmental factors to the design and development of products to improve the environmental performance of cooking appliances in their life cycle and optimize the environmental impact of cooking appliances. Eco-design takes into consideration of selection, production, sales, utilization, recycle and disposal of raw materials in products design and development stage pursuant to the concept of whole life cycle, to minimize resources consumption in the whole life cycle, use as little as possible or eliminate toxic and harmful raw materials, and reduce the generation and emission of pollutants so as to achieve environmental protection. Eco-design is the key to pollution prevention, while pollution prevention is the fundamental way to change the development mode of "treatment after pollution". Researches show that $80 \%$ of resources consumption and environmental influence depends on the product design stage, when full consideration will be given to existing technical conditions and raw materials guarantee. Optimizing and solving resources and environmental problems at each stage can realize resource saving to the greatest extent and reduce environmental pollution from the source $[1,2]$.

What to be done at the eco-design stage includes determining the products to be designed, and the purposes, plan and organization, demand analysis, preparation of design specifications, design of products and implementation, and completion of the project design, overall scheme design, system design, engineering design and other relevant documents. In the process of design, consideration will be given to the requirements for disposal (re-usage, recycling and treatment) of products at the end (expiry) of their life cycle, and the selection of appropriate handling method to assess the cost. Product design aids that are compatible with the environment will be selected and applied, such as life cycle assessment (LCA), to optimize product design. The method for final disposal of products will be subject to the principle of least environmental influence.

\section{DOMESTIC AND INTERNATIONAL BACKGROUND FOR GREEN DESIGN OF COOKING APPLIANCES}

The European Parliament and the Council of the

\footnotetext{
* Corresponding author: zongjf@enis.ac.cn
} 
European Union issued the ERP order (No. 2009/125/EC) in 2009, i.e. Framework for the Setting of Eco-design Requirements for Energy-related Products, which includes the instructions for cooking appliances. In the same year, China issued General Principles and Requirements of Eco-design for Products (GB/T 242562009[3]) which stipulates the general principles and requirements of eco-design of products. Moreover, China issued General Principles for Eco-design Product Assessment (GB/T 32161-2015[4]) in 2015 which stipulates the principles and methods of eco-design product assessment, requirements of assessment, and the method for preparation of a LCA report. Based on these two significant standards in the field of eco-design, combined with the development status of eco-design in the cooking appliances industry in China and pursuant to General Principles and Requirements of Eco-design for Products (GB/T 24256-2009), detailed requirements for cooking appliances were made, and the cooking appliances designed according to these standards conform to the requirements for eco-design set out in the General Principles for Eco-design Product Assessment (GB/T 32161-2015).

At present, theoretical researches are in a great number, and the number of standards is gradually increasing. However, eco-design standards for a wide range of consumable electronics are insufficient, and the products with eco-design are developed slowly. The main reason is that many enterprises produce OEM products and the design technology, which is in the hands of foreign companies. As a result, these enterprises are in no hurry to pay attention to researches on eco-design and thus lack their own eco-design system. Meanwhile, for the lack of competence in carrying researches of the kind, many small and medium-sized enterprises can hardly establish their own eco-product development system in a short period of time; they're possibly waiting for national policies and the promotion and application of technological achievements made by large-scale enterprises. Some domestic enterprises capable of research and products development haven't established their own eco-products research and development system, and are performing badly especially in the following aspects:

(1) They have not established a standard eco-design system. At present, several foreign enterprises have started to assess ecological attributes of products from the environmental impact in product life cycle, while most domestic enterprises are still stuck on single indicators to measure products with eco-design, such as free of CFC, energy conservation, low noise, etc. That is not an eco-design standard in a real sense.

(2) In China, there is still a shortage of complete and systemic systems for evaluation and assessment on ecodesign, there is a lack of complete laws and regulations, and thus great effort should be made by competent authorities for eco-design.

(3) Foreign enterprises have not only made ecodesign of their products related to consciousness and concept, but also set particular methods of operation and fundamental platforms for evaluation and management, and have promoted such methods and platforms from products design to the eco-design and management of product chain. However, domestic Chinese enterprises are still working on concepts, and are short of controllable design criterion and feasible and systematic design procedures, as well as lack basic engineering design data and design pattern as the support.

(4) For substitution of poisonous and harmful materials, researches on lead-free solder have been conducted by several individual organizations, from which results have been obtained from the laboratory but have not yet been popularized and applied.

\section{PURPOSES AND BASIC PRINCIPLES OF ECO-DESIGN OF COOKING APPLIANCES}

The eco-design of cooking appliances aims at reducing the environmental influence at the design, raw materials selection, production, packaging, transportation, distribution, utilization, scrapping, and subsequent treatment and disposal of products through green design, reducing the pollution from cooking appliances towards the environment, improving the recycling rate of cooking appliances to lessen the adverse impact of cooking appliances on the environment in the whole product life cycle, developing green design methods for modularized, waste-minimized and hazard-free products, and creating ecological, economic and sustainable cooking appliances system.

Basic principles of eco-design of cooking appliances include: demand orientation, advanced technology, scientific methods, environmentally friendly, economic rationality and compliance with laws.

The principle of demand orientation means that ecodesign should be oriented by comprehensive demand: the requirement of integrated utilization of cooking appliances and resources in the related system should be considered from the overall perspective; the environmental requirements at all stages of the whole product life cycle of cooking appliances should be considered from the perspective of process, especially at the utilization and scrapping stages; customized design should be applied from the perspective of performance to avoid functional waste and make the function of cooking appliances exactly meet system requirements.

The principle of advanced technology means that eco-design should be based on appropriate techniques: selection of advanced design techniques in priority; pursuing improvement of environmental indicators of cooking appliances without reducing their technical performance indicators; taking feasible manufacturing technologies as a basis; waste-minimized design of products; applying relatively mature environmental technologies; reducing the complexity of integrated technology and combined with design techniques.

The principle of scientific methods means that ecodesign should be based on scientific theories, such as theory of circular economy, theory of industrial ecology, and the theory of life cycle.

The environmentally friendly principle means that eco-design should aim at environmental protection: 
priority should be given to environmentally friendly and advanced techniques during eco-design of cooking appliances. Safety of cooking appliances should be guaranteed in the process of manufacturing, utilization, maintenance and final disposal. Efforts should be made to pursue waste minimization, re-usage and recycling of cooking appliances, at the time of ensuring product functions to improve the environmental influence in product life cycle, especially the environmental influence at the utilization and scrapping disposal stages. In addition to consideration of environmental influence of the cooking appliance itself, attention should be paid to the improvement of integrated performance of cooking appliances to reduce secondary pollution.

The principle of economic rationality means that ecodesign should be based on economic suitability: attention should be paid to environmental interests of cooking appliances, including environmental benefits and environmental costs; environmental interests should involve the enterprise, the customer and the society; rational environmental technology should be applied.

The principle of compliance with laws means that eco-design should be subject to laws and regulations: meeting restrictive requirements prescribed in national and international laws and regulations; technical standards and voluntary agreement; the needs, development trends and expectations of the market or consumers; and the expectations of the society and investors.

\section{REQUIREMENTS FOR ECO-DESIGN OF COOKING APPLIANCES}

\subsection{Stages of a life cycle}

Stages of a life cycle considered for eco-design of cooking appliances should include: acquisition, selection and utilization of environmentally friendly raw materials which meet RoHS specifications; product design and manufacturing; packaging, transportation and dispatch (attention should be given to the utilization of foam, and the recycling of packaging materials in the process of packaging); maintenance and repair; utilization of products; service life of products; recycling and disposal.

\subsection{Environmental factors}

Environmental factors to be evaluated at each stage of the life cycle should include: consumption of resources and energy; selection of materials meeting RoHS specifications; categories and quantities of hazardous emissions, such as $\mathrm{CO}, \mathrm{CO} 2$ and $\mathrm{NOx}$; pollution from physical effects such as noise, radiation and electromagnetic fields; gas appliances and fittings which should meet the requirements for safety and environmental performance in relevant codes; wastes generated, recycling (re-usage, recycling, energy recovery, etc.).

\subsection{Laws and regulations and other technical requirements}

Requirements of mandatory environmental laws and regulations include: energy efficiency standard, noise and electromagnetic compatibility, environmental protection laws related to production processes; specifications for subsequent installation of products; limits of the recovery ratio and recycling ratio. Requirements of non-mandatory environmental laws and regulations include: requirements for hazardous substance in materials, and requirements for hazardous substance in packages. Requirements for eco-technology not explicitly stipulated in laws and regulations include: minimizing the quantity of parts and components and the categories, and quantity of materials; improving standardization and generalization rates; adopting the equivalent design principle to the greatest extent; facilitating maintenance, repair, disassembly, warehousing and delivery.

\section{PROCESS AND KEY POINTS FOR ECO-DESIGN OF COOKING APPLIANCES}

Development of cooking appliances include seven parts, namely demand design, concept design, overall scheme design, systematic design, engineering design, reliability design and reliability evaluation plan design. Different key eco-design points are required at different design stages. A general requirement analysis is needed before concept design of cooking appliances, which includes external demands analysis (user demands analysis, seller demands analysis and supplier demands analysis), internal demands analysis; stakeholders demands analysis.

At the concept design stage, attention should be paid, under the prerequisite of meeting relevant laws and regulations, to weighing and optimizing the following parameters: functions of cooking appliances: air tightness, thermal load, thermal efficiency, combustion conditions, temperature rise, electric ignition device, flame-out protection, intelligence, corrosion resistance and durability of cooking appliance cap materials, pressure-bearing performance of packaging; energy efficiency index; noise; convenience for usage of products; standardization of mounting dimension of cooking appliances and the standardization of the interface between the power supply and the cooking appliance; product safety protection, such as dry burning-resistant protection and fire protection; antienvironment interference, such as electromagnetic interference and electromagnetic compatibility; service life of products; exhaust emissions ( $\mathrm{CO}, \mathrm{CO} 2, \mathrm{NOx})$; cost.

At the overall scheme design stage, attention should be paid, under the prerequisite of meeting relevant laws and regulations, to weighing and optimizing the following parameters: materials efficiency including the utilization ratio and production efficiency of materials; environmental performance of components 
manufacturing processes; energy efficiency index; noise; standardization and generalization rate; recovery ratio; exhaust emissions (CO, $\mathrm{CO} 2, \mathrm{NOx})$; re-usage rate.

Systematic design is classified into the design of valves, the design of combustion system, the design of control systems, etc., involving the structure of a stove, roaster, oven, rice cooker and parts and components. Please refer to GB16410[5]. For systematic design and parts design, attention should be paid, under the prerequisite of meeting relevant laws and regulations, to weighing and optimizing the following parameters: categories and quantities of materials, including selection of renewable and recoverable materials and distinction of renewable and non-renewable materials; recyclability of materials; renewability of materials; limits on the content of toxic and harmful substances in materials; standardization of parts and components, environmental performance and alternative of parts manufacturing process, and the recycling of packaging materials; detachability of the structure.

At the engineering design stage, attention should be paid, under the prerequisite of meeting relevant laws and regulations, to weighing and optimizing the following parameters: technological processes, especially key inspection procedures of fire test and leakage test; processing equipment, testing equipment, tooling, tools and molds; selection and consumption of auxiliary materials; limits on the content of toxic and harmful substances in auxiliary materials; energy consumption, noise and pollutant emission in manufacturing processes.

\section{METHODS OF ECO-DESIGN OF COOKING APPLIANCES}

Methods of eco-design of cooking appliances include: life cycle design method and modularity design method, which can be adopted individually or in combination. Eco-design involves but is not limited to these methods.

\subsection{Life cycle design method}

Life cycle design should be systematic at each stage of raw materials acquisition, manufacturing and processing, usage and maintenance, usage improvement and final disposal to improve the efficiency of resource utilization and environmental influence by means of continuous improvement. Life cycle design should involve demand analysis, concept design, structure design, and detailed design of products, which can be combined with modularity design and other design methods concurrently. The service stage is a key link in the life cycle of cooking appliances, so the design target at this stage should be improving the efficiency of resource utilization, reducing operation failures and shortening the downtime for maintenance and repair.

The life cycle design process mainly includes requirement decomposition, design analysis, target identification, technology R\&D, design improvement and life cycle evaluation. Life cycle evaluation is correlated to steps of the basic process, as shown in Figure 1. Ecological requirements are decomposed at each stage of the product life cycle, the current situation of products eco-design is analyzed, key design improvement objectives are identified, feasible technical implementation schemes are explored, products design is improved environmentally, and a LCA is made for cooking appliances to support the steps of the basic process. Please see GB/T 24040[6] for principles of LCA.

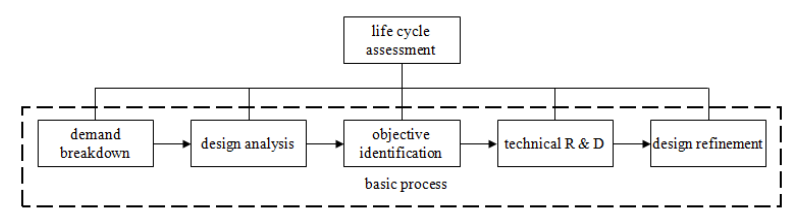

Fig. 1, Main process of cooking appliance product life cycle design

The life cycle design is a generic technology for ecodesign of cooking appliances. Its main ecological functions are as follows: it intends to allow people to consider ecological issues from a life cycle perspective and improve the overall importance of eco-design; it intends to identify key targets and main links to improve the pertinence of eco-design; it intends to implement the research and develop technologies around key issues to facilitate the breakthrough of key technologies of ecodesign; and it also intends to improve eco-design standards throughout the life cycle and at each stage.

\subsection{Modularity design method}

Modularity design means that a cooking appliance can be decomposed, based on the customer's demand and with the concept of system engineering, into several serialized and generalized modules with independent functions, and easy to be reused and modified to constitute a personalized product through combination. Modularity design should be oriented to the entire cooking appliance product family for full use of the similarity and reusability of modules, to effectively control the diversification of cooking appliances. Modularity design can be divided into the modularity design of new cooking appliances and the modularity design of existing cooking appliances, of which the former is the innovation of product structure and modules, while the latter is the rationalization of product structure and modules. Modularity design can be supported by informatization.

The modularity design process mainly includes module partition, module standardization, product modeling, configuration design, variant design and modular evaluation; LCA correlates with modularity design process and custom design process, as shown in Figure 2. Please see GB/T 30438[7] for principles of module partition of cooking appliances. Module partition, module standardization and cooking appliance modeling constitute the module design process, while configuration design and variant design constitute the product custom design process. Modularity evaluation, which is of value for comparison of similar products, is 
conducted to support the module design process and the custom design process.

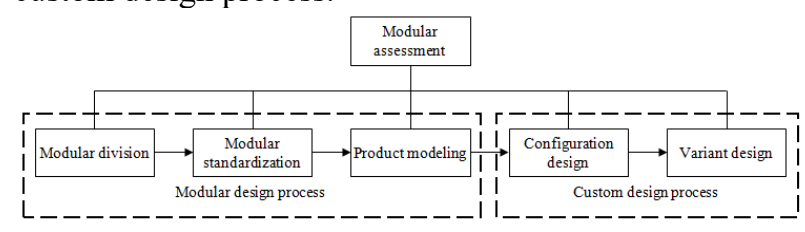

Fig. 2, Main process of modularity design

Modularity design is a generic technology for ecodesign of cooking appliances. Its main ecological functions are as follows : it intends to support the rapid custom design, satisfy customers' individual needs and avoid waste of resource; it intends to improve modular production lot, achieve scale benefits and make full use of the efficiency of manufacturing resources; it intends to facilitate usage and maintenance, reduce the loss from downtime, and extend product service life; it intends to realize detachability and facilitate the re-usage and regeneration of parts and components; and it also intends to support the product improvement environmentally through module improvement.

\section{EVALUATION AND IMPROVEMENT OF ECO-DESIGN OF COOKING APPLIANCES}

Principles of indicators setting for evaluation on cooking appliances include the principle of orientation, the principle of overall importance, the principle of simplicity and the principle of comparability. First, the principle of orientation: with an evaluation indicator system and several evaluation indicators established, emphasis of eco-design is shown, to promote safe and environmentally feasible technologies and guide the development of eco-design of cooking appliances. Second, the principle of overall importance: the evaluation indicator system should be oriented to the whole design process, the entire product life cycle of cooking appliances and the cooking appliance product family. Third, the principle of simplicity: the evaluation indicators should be simple, clear and easy to operate. Fourth, the principle of comparability: the evaluation indicators should be comparable for cooking appliances of the same kind. Eco-design evaluation is an iterative process running throughout the whole process of ecodesign, including such stages as preparation of specifications for product design, preliminary design of the product and implementation of the design. What to be evaluated mainly includes: the suitability of design aids, technical feasibility of design scheme, environmental impact assessment, economic evaluation, evaluation of compliance with the target and principles, etc. Evaluation on eco-design of cooking appliances is divided into process evaluation and evaluation on the ecological level of the product.

Process evaluation can be carried out according to the above-mentioned evaluation indicators, by comparison with similar products, system or parts and components created in a recent period. The evaluation method can be a radar chart or LCA; if the process evaluation can hardly meet the requirement, targeted measures may be put forward for improvement and a reevaluation may be made until the requirements of evaluation indicators are met.

After the eco-design of cooking appliances is completed, final evaluation should be made according to seven indicators, namely, energy efficiency index, noise, materials efficiency, product service life, hazardous emissions, recovery ratio, and re-usage ratio. The evaluation method can be radar chart. Cooking appliance manufacturers should establish and implement environmental management system and hazardous substance management system. The environmental management system should conform to GB/T 24001[8].

After the cooking appliances are released and before the life cycle expires, the product manufacturer should continuously improve the eco-design of products or repairable parts.

\section{PROVISION AND SHARING OF INFORMATION ABOUT COOKING APPLIANCES}

Laws and regulations related to eco-design of cooking appliances should be collected and sorted out, to allow stakeholders to communicate and exchange information about the supply chain, and abide by such relevant laws and regulations. Cooking appliance manufacturers should prepare company standards and specifications for eco-design of cooking appliances, and communicate and exchange them with stakeholders. After the eco-design of cooking appliances is completed, relevant information about eco-design may be communicated to and shared by stakeholders.

\section{CONCLUSION}

Eco-design of cooking appliances is a significant driving force to promote cooking appliance manufacturers to reduce resource and energy consumption, pollutants and greenhouse gas emission from the source, and update the process technology towards energy saving, low carbon and green techniques, thus to promote industrial transformation and upgrading. Under the premise of meeting users' requirements for functions, products should be guaranteed with high efficiency of materials and energy, degradability, bio-security, low emission, low toxicity and low hazard or non-poisonous and harmless in the whole product life cycle including design, production, usage, scrapping and disposal, which shall be the core ideology of eco-design of consumer electronics. The ecological damage caused by the development and application of modern science and technology needs to be confronted with by our human beings directly, while more rational and ecological decisions can be made for users by virtue of ecological products. 


\section{Acknowledgement}

This paper is funded by National key research and development plan project "Research on key technology standards of eco-design for consumer electronics and other important products" (2017YFF0207901).

\section{References}

1. Jianfang Zong and Jianhua Chen, Comparative Analysis and Research on Domestic and Foreign Mechanism of Ecological Evaluation of Products, China Standardization, 2017, (15):54-58 .

2. Jianfang Zong, Jianwei Tian, Dongfeng Guo, Liang Chen, A study on the eco-design of consumer electronics; E3S Web of Conference 53, 04003(2018).

3. GB/T 24256-2009, General Principle and Requirements of Eco-design for Products

4. GB/T 32161-2015, General Principles for Ecodesign Product Assessment

5. GB16410, Domestic Gas Cooking Appliances

6. GB/T 24040, Environmental management-Life cycle Assessment-Principles and Frameworks

7. GB/T 30438, Principles and Methods for Data Dictionary Technology of Supporting Modularity Design

8. GB/T 24001, Environmental Management SystemSpecifications with Guidance for Use (GB/T 240012004, ISO 14001: 2004, IDT) 